\title{
Testosterone levels and cause-specific mortality in the older French men without metabolic syndrome
}

\author{
Nasser Laouali', Sylvie Brailly-Tabard ${ }^{2,3}$, Catherine Helmer ${ }^{4}$, Marie-Laure Ancelin ${ }^{5}$, \\ Christophe Tzourio ${ }^{6}$, Alexis Elbaz ${ }^{1}$, Anne Guiochon-Mantel ${ }^{2,3}$, Marianne Canonico' \\ 'Paris-Saclay University, Paris-South University, UVSQ, Center for Research in Epidemiology and Population Health, INSERM, Villejuif, France; \\ ${ }^{2}$ Service de Génétique Moléculaire, Pharmacogénétique et Hormonologie, Hôpitaux Universitaires Paris Sud, AH-HP, CHU Bicêtre, Le Kremlin \\ Bicêtre, France; ${ }^{3}$ INSERM UMR_S U1 185, Fac Med Paris Sud, University Paris Sud, Université Paris-Saclay, Le Kremlin Bicêtre, France; ${ }^{4}$ University \\ Bordeaux, INSERM, Bordeaux Population Health Research Center, UMR 1219, CIC-1401-EC, F-33000 Bordeaux, Bordeaux, France; ${ }^{5}$ INSERM, \\ University Montpellier, Neuropsychiatry, Epidemiological and Clinical Research, Montpellier, France; ${ }^{6}$ University Bordeaux, INSERM, Bordeaux \\ Population Health Research Center, UMR 1219, CHU Bordeaux, F-33000 Bordeaux, Bordeaux, France
}

OBJECTIVES: Previous studies have reported controversial findings regarding the association of testosterone with mortality in older men. This heterogeneity might be partially explained by comorbidities and the presence of metabolic syndrome, as well as differential associations according to causes of death.

METHODS: We used data from a random subsample of the Three-City study, in which hormone levels were measured in 338 men $\geq 65$ years without metabolic syndrome who were followed-up for 12 years. Vital status was determined for all participants from different sources. We used inverse-probability-weighted Cox regression to estimate the hazard ratios (HRs) of cause-specific mortality and 95\% confidence intervals (CIs).

RESULTS: Over the follow-up period, 130 men died (30 from cardiovascular disease, 45 from cancer, 55 from other causes). The association of testosterone with mortality showed significant heterogeneity across causes of death ( $\mathrm{p}=0.027$ and $\mathrm{p}=0.022$ for total and bioavailable testosterone, respectively). Higher testosterone levels were associated with increased cardiovascular mortality (HR for 1-standard deviation increase, 1.86; 95\% CI, 1.28 to 2.71 and 1.50; 95\% CI, 1.04 to 2.17 for total and bioavailable testosterone, respectively). By contrast, there were no significant associations of testosterone with mortality from cancer and other causes.

CONCLUSIONS: Our data suggest that the association of testosterone with mortality in men without metabolic syndrome might be differential according to the cause of death. These findings may partially explain the heterogeneity across studies on the relationship between testosterone levels and mortality.

KEY WORDS: Ageing, Cancer mortality, Cardiovascular diseases mortality, Risk, Testosterone, Metabolic syndrome

\author{
Correspondence: Marianne Canonico \\ Center for Research in Epidemiology and Population Health, \\ 16 Avenue Paul Vaillant Couturier, Villejuif 94807, France \\ E-mail: marianne.canonico@inserm.fr \\ Received: Apr 10, 2020 / Accepted: Jun 1, 2020 / Published: Jun 1, 2020 \\ This article is available from: https://e-epih.org/ \\ (c) This is an open-access article distributed under the terms of the Creative \\ Commons Attribution License (https://creativecommons.org/licenses/by/4.0/), \\ which permits unrestricted use, distribution, and reproduction in any medium, \\ provided the original work is properly cited. \\ (C) 2020, Korean Society of Epidemiology
}

\section{INTRODUCTION}

Findings from studies on the relationship between testosterone levels and mortality in men are highly heterogeneous, making it difficult to draw clear conclusions [1]. Identifying possible sources of heterogeneity may help better understand this relationship and to determine which groups are at higher risk. In a previous analysis, we reported that metabolic syndrome (MetS) could partially explain this heterogeneity, as there was an inverse association between testosterone and all-cause mortality in men with MetS, but not in those without MetS [2]. However, it is possible that testosterone plays a stronger role in specific causes of death, explaining 
the lack of association between testosterone and all-cause mortality in men without MetS. Indeed, testosterone was positively associated with cardiovascular (CV) events $[3,4]$ but negatively with cancer [5], suggesting differential associations of testosterone with health outcomes. Nevertheless, MetS was not taken into account and no study has examined this differential risk in a metabolically "healthy" population. Specific research that enables the identification of subgroups of men at higher risk would be very important for clinical practice when considering, for example, testosterone therapy or other specific treatments. Therefore, the aim of the present study was to examine the relationship between plasma testosterone and cause-specific mortality in men without MetS.

\section{MATERIALS AND METHODS}

The protocol of the Three-City (3C) study, a French prospective cohort study, is available elsewhere [2,6,7]. Briefly, 9,294 non-institutionalized subjects $\geq 65$ years of age were selected from the electoral rolls of 3 French cities (Bordeaux, Dijon, and Montpellier) between 1999 and 2001 and interviewed 5 times (every 2 to 3 years) thereafter.

Over the 12-year follow-up, the vital status of each participant was determined based on medical records and reports from the participant's family and physicians. A committee reviewed these data to determine immediate and underlying causes of death, according to International Classification of Diseases, 10th revision codes. Our analyses are based on the 3 main causes of death: CV, cancer, and other causes, as described elsewhere [7].

Baseline total and bioavailable testosterone were measured in a random subsample representing one-seventh of the men from the original cohort, after stratification by gender, center, and age [2]. Total testosterone was assessed by a radioimmunoassay (RIA) method with an Orion Diagnostica device (Spectria, Espoo, Finland) and a minimum detectable concentration of $0.06 \mathrm{nmol} / \mathrm{L}$; all testosterone assays were detectable. The intra-assay and interassay coefficients of variation were $3.8 \%$ and $4.8 \%$, respectively, for a total testosterone concentration of $10.2 \mathrm{nmol} / \mathrm{L}$ and $4.8 \%$ and $5.5 \%$, respectively, for a total testosterone concentration of $21.3 \mathrm{nmol} / \mathrm{L}$.

MetS was defined according to the Diabetes Federation $[2,8]$. Body mass index (BMI) was calculated by dividing weight (kg) by squared height $\left(\mathrm{m}^{2}\right)$. Smoking status and daily alcohol consumption were considered in 3 categories (never, past, current). Education level was categorized into 3 groups (no education or primary school, secondary school, and high-school or university degree). Hypertension was defined according to the World Health Organization criteria (systolic blood pressure $\geq 140 \mathrm{mmHg}$ and/or diastolic blood pressure $\geq 90 \mathrm{mmHg}$ and/or blood-pressure-lowering therapy). Hypercholesterolemia was defined as total cholesterol $\geq 6.2 \mathrm{mmol} / \mathrm{L}$ and/or cholesterol-lowering therapy, and diabetes as fasting blood glucose $\geq 7 \mathrm{mmol} / \mathrm{L}$ and/or antidiabetic drugs. A personal history of $\mathrm{CV}$ disease at baseline included coronary heart disease (myocardial infraction, angina pectoris, coronary dilation) and stroke.

The baseline characteristics of the participants are expressed as means \pm standard deviation (SD), medians (interquartile range), or numbers (percentage) for categorical variables. Their distributions according to causes of death and tertiles of total testosterone were compared using the chi-square test, the Student t-test, or analysis of variance.

We used Cox proportional hazards regression models with age as the time scale to estimate hazard ratios (HRs) and 95\% confidence intervals (CIs) for cause-specific mortality [9]. Participants were followed-up from baseline to the date of death from a specific cause or censoring (death from another cause or date of last confirmation that they were alive).

Model 1 was adjusted for center; model 2 was further adjusted for confounders (smoking, alcohol drinking, education level, history of CV disease, hypertension, hypercholesterolemia, diabetes, BMI). We created extra categories for covariates with missing values to keep the same number of subjects in the analyses.

In sensitivity analyses, we excluded deaths occurring during the first 2 and 4 years of follow-up.

We used a stabilized inverse-probability-weighting approach to take into account the fact that testosterone was measured in a random subcohort [10]. Weights were calculated for each individual as detailed elsewhere [2].

Statistical analyses were performed using SAS version 9.4 (SAS Institute Inc., Cary, NC, USA).

\section{Ethics statement}

The study protocol was approved by the Ethics Committee of the University Hospital of Kremlin-Bicêtre, and all participants gave written informed consent.

\section{RESULTS}

From the random subcohort of 495 men, we excluded 22 men who received treatments that might influence hormone levels or had a history of prostate cancer or prostatitis, 29 men without data on MetS, and 106 men with MetS. The remaining 338 men without MetS constituted the sample for our analysis.

Over 12 years of follow-up, 130 men died (38.5\%): 30 from CV disease, 45 from cancer, and 55 from other causes. Compared to survivors, they were older at baseline and more likely to be current smokers and daily alcohol drinkers (for deaths from cancer) than those who were alive at the end of follow-up, independently of their age at inclusion (Table 1). As expected, men with the highest levels of testosterone were less likely to present diabetes (Supplementary Material 1).

Total and bioavailable testosterone were not significantly associated with all-cause mortality in men without MetS (HR for 1-SD increase, 1.08 ; $95 \%$ CI, 0.80 to 1.46 and 0.97 ; $95 \%$ CI, 0.73 to 1.29 , respectively) but there was significant heterogeneity across causes of death ( $p=0.027$ and $p=0.022$, respectively).

The associations of baseline endogenous hormone levels with 
Table 1. Baseline characteristics of men without MetS according to cause-specific mortality after a 12-year follow-up in the $3 \mathrm{C}$ cohort study

\begin{tabular}{|c|c|c|c|c|c|c|c|c|c|c|}
\hline Characteristics & $\begin{array}{c}\text { Alive } \\
(n=208)\end{array}$ & $\begin{array}{l}\text { CV disease } \\
\text { mortality } \\
(n=30)\end{array}$ & $p$-value ${ }^{1}$ & $p$-value ${ }^{2}$ & $\begin{array}{l}\text { Cancer } \\
\text { mortality } \\
(\mathrm{n}=45)\end{array}$ & $p$-value ${ }^{1}$ & $p$-value ${ }^{2}$ & $\begin{array}{l}\text { Other cause } \\
\text { mortality } \\
(n=55)\end{array}$ & p-value ${ }^{1}$ & p-value ${ }^{2}$ \\
\hline \multicolumn{11}{|l|}{ Socio-demographic } \\
\hline Age (yr) & $71.8 \pm 4.3$ & $76.3 \pm 4.2$ & $<0.001$ & - & $75.6 \pm 4.8$ & $<0.01$ & - & $77.4 \pm 5.0$ & $<0.01$ & - \\
\hline Center & & & 0.097 & 0.179 & & 0.973 & 0.958 & & 0.608 & 0.749 \\
\hline Bordeaux & $38(18.3)$ & $10(33.3)$ & & & $8(17.8)$ & & & $13(23.6)$ & & \\
\hline Dijon & $107(51.4)$ & $15(50.0)$ & & & $24(53.3)$ & & & $28(50.9)$ & & \\
\hline Montpellier & $63(30.3)$ & $5(16.7)$ & & & $13(28.9)$ & & & $14(25.5)$ & & \\
\hline Education level & & & 0.764 & 0.847 & & 0.175 & 0.161 & & 0.646 & 0.714 \\
\hline No education or primary school & $49(23.6)$ & $8(26.7)$ & & & $15(33.3)$ & & & $14(25.5)$ & & \\
\hline Secondary school & $54(26.0)$ & $9(30.0)$ & & & $14(31.1)$ & & & $17(30.9)$ & & \\
\hline High-school or university degree & $105(50.4)$ & $13(43.3)$ & & & $16(35.6)$ & & & $24(43.6)$ & & \\
\hline \multicolumn{11}{|l|}{ CV risk factors } \\
\hline BMI $\left(\mathrm{kg} / \mathrm{m}^{2}\right)^{3}$ & $25.4 \pm 2.8$ & $26.4 \pm 2.7$ & 0.052 & 0.141 & $25.7 \pm 2.9$ & 0.459 & 0.551 & $25.0 \pm 3.6$ & 0.451 & 0.225 \\
\hline Smoking & & & 0.043 & 0.044 & & 0.019 & 0.024 & & 0.910 & 0.823 \\
\hline Never & $62(29.8)$ & $15(50.0)$ & & & $12(26.7)$ & & & $15(27.3)$ & & \\
\hline Past & $132(63.5)$ & $12(40.0)$ & & & $24(53.3)$ & & & $36(65.4)$ & & \\
\hline Current & $14(6.7)$ & $3(10.0)$ & & & $9(20.0)$ & & & $4(7.3)$ & & \\
\hline Daily alcohol consumption & & & 0.285 & 0.233 & & 0.070 & 0.025 & & 0.157 & 0.098 \\
\hline Never & $197(94.7)$ & $27(90.0)$ & & & $40(88.9)$ & & & $49(89.1)$ & & \\
\hline Past & $7(3.4)$ & $2(6.7)$ & & & $1(2.2)$ & & & $3(5.5)$ & & \\
\hline Current & $4(1.9)$ & $1(3.3)$ & & & $4(8.9)$ & & & $3(5.5)$ & & \\
\hline Hypertension & $139(66.8)$ & $23(76.7)$ & 0.280 & 0.857 & $34(75.6)$ & 0.254 & 0.404 & $45(81.8)$ & 0.031 & 0.582 \\
\hline Hypercholesterolemia & $90(43.3)$ & $14(46.7)$ & 0.726 & 0.990 & $13(28.9)$ & 0.075 & 0.939 & $21(38.2)$ & 0.497 & 0.113 \\
\hline Diabetes & $10(4.8)$ & $1(3.3)$ & - & - & $2(4.4)$ & - & - & $6(10.9)$ & 0.112 & 0.560 \\
\hline \multicolumn{11}{|l|}{ Medical history } \\
\hline Coronary heart disease & $22(10.6)$ & $6(20.0)$ & 0.134 & 0.617 & $4(8.9)$ & 0.718 & 0.387 & $10(18.2)$ & 0.125 & 0.119 \\
\hline Stroke ${ }^{4}$ & $4(2.0)$ & $1(3.5)$ & - & - & $1(2.2)$ & - & - & $4(7.7)$ & 0.056 & 0.304 \\
\hline \multicolumn{11}{|l|}{ Biological parameters } \\
\hline Total cholesterol (mmol/L) & $5.6 \pm 0.8$ & $5.6 \pm 1.1$ & 0.798 & 0.552 & $5.6 \pm 0.8$ & 0.786 & 0.628 & $5.5 \pm 0.9$ & 0.282 & 0.833 \\
\hline $\mathrm{LDL}-\mathrm{C}(\mathrm{mmol} / \mathrm{L})^{5}$ & $3.6 \pm 0.7$ & $3.6 \pm 1.0$ & 0.995 & 0.450 & $3.5 \pm 0.8$ & 0.604 & 0.926 & $3.4 \pm 0.7$ & 0.142 & 0.778 \\
\hline $\mathrm{HDL}-\mathrm{C}(\mathrm{mmol} / \mathrm{L})$ & $1.5 \pm 0.3$ & $1.4 \pm 0.3$ & 0.128 & 0.274 & $1.5 \pm 0.3$ & 0.919 & 0.930 & $1.5 \pm 0.3$ & 0.969 & 0.864 \\
\hline Triglycerides (mmol/L) & $1.0[0.8-1.3]$ & $1.1[0.9-1.4]$ & 0.298 & 0.189 & $1.1[0.9-1.5]$ & 0.212 & 0.175 & $1.0[0.8-1.3]$ & 0.634 & 0.256 \\
\hline Glucose (g/L) & $4.9[4.6-5.2]$ & $4.9[4.5-5.1]$ & 0.520 & 0.611 & $4.9[4.6-5.1]$ & 0.857 & 0.914 & $4.9[4.6-5.5]$ & 0.153 & 0.055 \\
\hline Total testosterone $(\mathrm{nmol} / \mathrm{L})$ & $17.7 \pm 5.8$ & $20.8 \pm 7.4$ & 0.037 & 0.011 & $18.0 \pm 6.0$ & 0.774 & 0.851 & $17.7 \pm 6.9$ & 0.969 & 0.988 \\
\hline Bioavailable testosterone $(\mathrm{nmol} / \mathrm{L}$ ) & $10.5 \pm 3.4$ & $11.7 \pm 3.5$ & 0.083 & 0.067 & $9.9 \pm 3.0$ & 0.307 & 0.511 & $10.1 \pm 3.9$ & 0.520 & 0.685 \\
\hline
\end{tabular}

Values are presented as number (\%) or mean \pm standard deviation except for triglycerides and glucose levels, which are expressed as medians [interquartile range].

MetS, metabolic syndrome; 3C, Three-City; CV, cardiovascular; BMI, body mass index; LDL-C, low-density lipoprotein cholesterol; HDL-C, high-density lipoprotein cholesterol.

${ }^{1} \mathrm{t}$-test or chi-square test.

${ }^{2}$ Cochran-Mantel-Haenszel statistic or analysis of variance adjusted for age.

${ }^{3}$ Missing data: $\mathrm{n}=1$.

${ }^{4}$ Missing data: $n=6$.

${ }^{5}$ Missing data: $\mathrm{n}=2$.

cause-specific mortality are presented in Table 2. Higher total and bioavailable testosterone levels were positively associated with $\mathrm{CV}$ mortality (HR for 1-SD increase, 1.86; 95\% CI, 1.28 to 2.71 and $1.50 ; 95 \% \mathrm{CI}, 1.04$ to 2.17 , respectively). When testosterone level was categorized into tertiles, we observed a linear trend $(p=0.014$ and $\mathrm{p}=0.012$, respectively), with a higher incidence of $\mathrm{CV}$ death among participants in the top tertile compared to those in the bottom tertile (HR, 2.94; 95\% CI, 1.16 to 7.43 and 2.75, 95\% CI, 1.15 to 6.57 , respectively). There were no significant associations of total and bioavailable testosterone levels with mortality from cancer or other causes.

The results were similar after the exclusion of deaths occurring during the first 2 years and 4 years of follow-up (data not shown). 
Table 2. Cause-specific mortality in men without MetS according to baseline testosterone levels

\begin{tabular}{|c|c|c|c|c|c|}
\hline & \multirow{2}{*}{$\begin{array}{l}\text { Events } \\
\text { (n) }\end{array}$} & \multicolumn{2}{|c|}{ Model $1(n=338)$} & \multicolumn{2}{|c|}{ Model $2(n=338)$} \\
\hline & & $\mathrm{HR}(95 \% \mathrm{Cl})$ & p-value & $\mathrm{HR}(95 \% \mathrm{Cl})$ & $\mathrm{p}$-value \\
\hline \multicolumn{6}{|l|}{ CV mortality } \\
\hline \multicolumn{6}{|c|}{ Total testosterone $(\mathrm{nmol} / \mathrm{L})$} \\
\hline For 1-SD increase & 30 & $1.61(1.16,2.23)$ & 0.004 & $1.86(1.28,2.71)$ & 0.001 \\
\hline $\mathrm{T} 1(<14.95)$ & 8 & 1.00 (reference) & - & 1.00 (reference) & - \\
\hline T2 (14.95-19.99) & 5 & $0.66(0.23,1.85)$ & 0.423 & $0.64(0.22,1.90)$ & 0.423 \\
\hline $\mathrm{T} 3(\geq 20.00)$ & 17 & $2.28(1.02,5.09)$ & 0.045 & $2.94(1.16,7.43)$ & 0.023 \\
\hline$p$ for linear trend & & & 0.022 & & 0.014 \\
\hline \multicolumn{6}{|c|}{ Bioavailable testosterone $(\mathrm{nmol} / \mathrm{L})$} \\
\hline For 1-SD increase & 30 & $1.41(1.02,1.95)$ & 0.039 & $1.50(1.04,2.17)$ & 0.029 \\
\hline $\mathrm{T} 1(<8.66)$ & 8 & 1.00 (reference) & - & 1.00 (reference) & - \\
\hline T2 (8.66-11.40) & 4 & $0.55(0.18,1.67)$ & 0.294 & $0.56(0.17,1.79)$ & 0.325 \\
\hline $\mathrm{T} 3(\geq 11.41)$ & 18 & $2.41(1.10,5.33)$ & 0.030 & $2.75(1.15,6.57)$ & 0.023 \\
\hline $\mathrm{p}$ for linear trend & & & 0.017 & & 0.012 \\
\hline \multicolumn{6}{|l|}{ Cancer mortality } \\
\hline \multicolumn{6}{|c|}{ Total testosterone (nmol/L) } \\
\hline For 1-SD increase & 45 & $1.05(0.79,1.39)$ & 0.744 & $1.00(0.73,1.35)$ & 0.981 \\
\hline $\mathrm{T} 1(<14.95)$ & 15 & 1.00 (reference) & - & 1.00 (reference) & - \\
\hline T2 (14.95-19.99) & 16 & $1.20(0.62,2.33)$ & 0.585 & $1.22(0.61,2.43)$ & 0.567 \\
\hline $\mathrm{T} 3(\geq 20.00)$ & 14 & $1.00(0.50,2.00)$ & 0.988 & $0.79(0.37,1.68)$ & 0.541 \\
\hline $\mathrm{p}$ for linear trend & & & 0.539 & & 0.232 \\
\hline \multicolumn{6}{|c|}{ Bioavailable testosterone $(\mathrm{nmol} / \mathrm{L})$} \\
\hline For 1-SD increase & 45 & $0.89(0.66,1.18)$ & 0.408 & $0.86(0.64,1.16)$ & 0.318 \\
\hline $\mathrm{T} 1(<8.66)$ & 16 & 1.00 (reference) & - & 1.00 (reference) & - \\
\hline T2 (8.66-11.40) & 17 & $1.13(0.60,2.16)$ & 0.702 & $1.19(0.60,2.32)$ & 0.621 \\
\hline $\mathrm{T} 3(\geq 11.41)$ & 12 & $0.79(0.39,1.61)$ & 0.513 & $0.65(0.30,1.40)$ & 0.269 \\
\hline$p$ for linear trend & & & 0.532 & & 0.239 \\
\hline \multicolumn{6}{|l|}{ Other-cause mortality } \\
\hline \multicolumn{6}{|c|}{ Total testosterone $(\mathrm{nmol} / \mathrm{L})$} \\
\hline For 1-SD increase & 55 & $1.14(0.87,1.49)$ & 0.357 & $1.08(0.80,1.46)$ & 0.601 \\
\hline $\mathrm{T} 1(<14.95)$ & 20 & 1.00 (reference) & - & 1.00 (reference) & - \\
\hline T2 (14.95-19.99) & 18 & $0.77(0.40,1.47)$ & 0.429 & $0.73(0.37,1.44)$ & 0.359 \\
\hline $\mathrm{T} 3(\geq 20.00)$ & 17 & $1.04(0.55,1.95)$ & 0.911 & $0.93(0.46,1.85)$ & 0.830 \\
\hline $\mathrm{p}$ for linear trend & & & 0.347 & & 0.411 \\
\hline \multicolumn{6}{|c|}{ Bioavailable testosterone $(\mathrm{nmol} / \mathrm{L})$} \\
\hline For 1-SD increase & 55 & $1.06(0.81,1.39)$ & 0.658 & $0.97(0.73,1.29)$ & 0.831 \\
\hline $\mathrm{T} 1(<8.66)$ & 20 & 1.00 (reference) & - & 1.00 (reference) & - \\
\hline T2 (8.66-11.40) & 19 & $1.00(0.53,1.89)$ & 0.997 & $0.94(0.48,1.83)$ & 0.856 \\
\hline $\mathrm{T} 3(\geq 11.41)$ & 16 & $1.06(0.56,2.04)$ & 0.852 & $0.94(0.47,1.88)$ & 0.855 \\
\hline $\mathrm{p}$ for linear trend & & & 0.346 & & 0.407 \\
\hline
\end{tabular}

Model 1: adjusted for age and center; Model 2: model 1+education level, smoking status, daily alcohol consumption, personal history of coronary disease and stroke, body mass index, diabetes, hypertension, and hypercholesterolemia.

MetS, metabolic syndrome; CV, cardiovascular; $\mathrm{HR}$, hazard ratio; $\mathrm{Cl}$, confidence interval; SD, standard deviation; T, tertile.

${ }^{1} \mathrm{HRs}$ and $95 \% \mathrm{Cls}$ were computed using inverse-probability-weighted Cox models.

\section{DISCUSSION}

In men without MetS, we found no significant association between testosterone and mortality overall, but we observed a differential association according to the cause of death. Independent- ly of $\mathrm{CV}$ risk factors, higher levels of testosterone increased the risk of CV mortality, but were not associated with mortality from cancer and other causes.

This positive association of testosterone with CV mortality differed from some previous studies that showed an inverse associa- 
tion [11-13] or no association $[14,15]$; however, there are important differences between these studies and ours that could account for these inconsistent findings. First, other studies analyzed younger subjects than those included in the $3 \mathrm{C}$, resulting in lower mortality rates. Second, these studies had shorter follow-up periods, and their findings may have been biased by reverse causation - that is, testosterone levels may have been influenced by the diseases that led to death. Reverse causation is less likely in the $3 \mathrm{C}$ study, given the longer follow-up and the findings of our subanalyses with the exclusion of participants who died early during the follow-up. Finally, previous studies did not take MetS status into account, while our analysis was limited to men without MetS who, by definition, have less comorbidities and are healthier compared to men overall. Conversely, our results are consistent with other studies on the risk of death from coronary heart disease $[16,17]$ and CV events $[3,4]$. This is also in keeping with a meta-analysis of 27 clinical trials $(\mathrm{n}=2,994 \mathrm{men})$ showing increased $\mathrm{CV}$ risk in men treated with exogenous testosterone compared to placebo [18].

The mechanisms underlying the positive association between testosterone and CV mortality remain unknown. One study hypothesized that high testosterone levels may promote fluid-sodium retention in aging men, thereby contributing to the development of high blood pressure and heart failure [19]. However, in our study, adjustment for hypertension did not have a noteworthy impact. Another study suggested that the use of anabolic steroids is associated with left ventricular hypertrophy [20], thus increasing the risk of $\mathrm{CV}$ mortality. Although our data do not concern exogenous testosterone, we cannot exclude a similar mechanism for endogenous testosterone.

With respect to cancer mortality, we found no significant association with testosterone, in agreement with several previous studies $[16,21,22]$; however, other studies have shown an inverse association between testosterone and risk of cancer mortality [5,23,24]. We could not examine specific cancers due to the low number of cases and we cannot exclude the possibility that some associations might exist for specific cancers. In addition, the people who agreed to participate in the $3 \mathrm{C}$ study were healthier than the general population [6], and there were few current smokers at baseline. Since smoking is a very strong risk factor for $\mathrm{CV}$ disease and cancer, especially for aero-pharyngeal cancers, this low smoking prevalence may have led to reduced statistical power.

The major limitation of our study is that our analyses were based on a random stratified subcohort of men, rather than on the whole cohort. In order to control for sampling-related biases, we used inverse-probability-weighting [10]. In addition, testosterone measurements were carried out by RIA, rather than the state-of-the-art gas chromatography mass spectrometry method. However, validation studies showed that RIA provided accurate results in terms of relative ranking and was therefore adequate for epidemiological investigations in which population-level inferences are more of interest than subject-specific ones. Finally, the $3 \mathrm{C}$ cohort, like most cohort studies, is not representative of the French general population aged 65 years and over. For example, the prevalence of some CV and cancer risk factors, such as smoking status and educational level, was underestimated when compared with the general population [6]. However, we verified well-known associations and therefore we expect that this issue would attenuate, but not bias, the associations. Nevertheless, extrapolating these results to the general population must therefore be done carefully.

In conclusion, among men without MetS, high testosterone levels were found to be associated with increased CV mortality, but not cancer mortality. These findings may partially explain the heterogeneity of studies on the relationship between testosterone and mortality and help clinicians to identify groups at high-risk.

\section{SUPPLEMENTARY MATERIALS}

Supplementary material is available at http://www.e-epih.org/.

\section{CONFLICT OF INTEREST}

The authors have no conflicts of interest to declare for this study.

\section{FUNDING}

This work was supported by the Fondation pour la Recherche Médicale for preparation and initiation of the study. The $3 \mathrm{C}$ is also supported by the Caisse Nationale d'Assurance Maladie des Travailleurs Salariés, Direction Générale de la Santé, Mutuelle Générale de l'Education Nationale, Institut de la Longévité, Conseils Régionaux of Aquitaine and Bourgogne, Fondation de France, Ministry of Research-INSERM Programme "Cohortes et collections de données biologiques," Agence Nationale de la Recherche (ANR PNRA 2006 and LongVie 2007), the "Fondation Plan Alzheimer" (FCS 2009-2012), and the Caisse Nationale de Solidarité pour l'Autonomie. The experiments complied with the current laws of the country in which they were performed. Biological assays regarding hemostatic and hormone parameters were supported by a grant from the Agence Nationale de la Recherche (ANR 2007-LVIE-005-01; principal investigator Pierre-Yves Scarabin).

\section{ACKNOWLEDGEMENTS}

None.

\section{AUTHOR CONTRIBUTIONS}

Conceptualization: MC. Data curation: MC. Formal analysis: NL, AE, MC. Funding acquisition: MC. Methodology: MC, AE, NL. Project administration: MC. Visualization: NL, SBT, CH, MLA, CT, AE, AGM, MC. Writing - original draft: NL, AE, MC. Writing - review \& editing: NL, SBT, CH, MLA, CT, AE, AGM, MC.

\section{ORCID}

Nasser Laouali: https://orcid.org/0000-0002-8532-456X; Sylvie 
Brailly-Tabard: https://orcid.org/0000-0001-5625-4833; Catherine Helmer: https://orcid.org/0000-0002-5169-7421; Marie-Laure Ancelin: https://orcid.org/0000-0002-1149-4320; Christophe Tzourio: https://orcid.org/0000-0002-6517-2984; Alexis Elbaz: https://orcid. org/0000-0001-9724-5490; Anne Guiochon-Mantel: https://orcid. org/0000-0003-1737-1409; Marianne Canonico: https://orcid.org/ 0000-0002-2843-8640

\section{REFERENCES}

1. Araujo AB, Dixon JM, Suarez EA, Murad MH, Guey LT, Wittert GA. Clinical review: endogenous testosterone and mortality in men: a systematic review and meta-analysis. J Clin Endocrinol Metab 2011;96:3007-3019.

2. Laouali N, Brailly-Tabard S, Helmer C, Ancelin ML, Tzourio C, Singh-Manoux A, et al. Testosterone and all-cause mortality in older men: the role of metabolic syndrome. J Endocr Soc 2018;2: 322-335.

3. Shores MM, Biggs ML, Arnold AM, Smith NL, Longstreth WT Jr, Kizer JR, et al. Testosterone, dihydrotestosterone, and incident cardiovascular disease and mortality in the cardiovascular health study. J Clin Endocrinol Metab 2014;99:2061-2068.

4. Soisson V, Brailly-Tabard S, Helmer C, Rouaud O, Ancelin ML, Zerhouni C, et al. A J-shaped association between plasma testosterone and risk of ischemic arterial event in elderly men: the French 3C cohort study. Maturitas 2013;75:282-288.

5. Khaw KT, Dowsett M, Folkerd E, Bingham S, Wareham N, Luben R, et al. Endogenous testosterone and mortality due to all causes, cardiovascular disease, and cancer in men: European prospective investigation into cancer in Norfolk (EPIC-Norfolk) Prospective Population Study. Circulation 2007;116:2694-2701.

6. 3C Study Group. Vascular factors and risk of dementia: design of the Three-City Study and baseline characteristics of the study population. Neuroepidemiology 2003;22:316-325.

7. Laouali N, Brailly-Tabard S, Helmer C, Ancelin ML, Tzourio C, Elbaz A, et al. Oestradiol level, oestrogen receptors, and mortality in elderly men: the three-city cohort study. Clin Endocrinol (Oxf) 2018;89:514-525.

8. Alberti KG, Zimmet P, Shaw J; IDF Epidemiology Task Force Consensus Group. The metabolic syndrome--a new worldwide definition. Lancet 2005;366:1059-1062.

9. Lau B, Cole SR, Gange SJ. Competing risk regression models for epidemiologic data. Am J Epidemiol 2009;170:244-256.

10. Lau B, Cole SR, Gange SJ. Competing risk regression models for epidemiologic data. Am J Epidemiol 2009;170:244-256.

11. Hyde Z, Norman PE, Flicker L, Hankey GJ, Almeida OP, McCaul $\mathrm{KA}$, et al. Low free testosterone predicts mortality from cardiovascular disease but not other causes: the Health in Men Study. J
Clin Endocrinol Metab 2012;97:179-189.

12. Yeap BB, Hyde Z, Almeida OP, Norman PE, Chubb SP, Jamrozik $\mathrm{K}$, et al. Lower testosterone levels predict incident stroke and transient ischemic attack in older men. J Clin Endocrinol Metab 2009; 94:2353-2359.

13. Maggio M, Basaria S. Welcoming low testosterone as a cardiovascular risk factor. Int J Impot Res 2009;21:261-264.

14. Srinath R, Hill Golden S, Carson KA, Dobs A. Endogenous testosterone and its relationship to preclinical and clinical measures of cardiovascular disease in the atherosclerosis risk in communities study. J Clin Endocrinol Metab 2015;100:1602-1608.

15. Vikan T, Schirmer H, Njølstad I, Svartberg J. Endogenous sex hormones and the prospective association with cardiovascular disease and mortality in men: the Tromsø Study. Eur J Endocrinol 2009;161:435-442.

16. Araujo AB, Kupelian V, Page ST, Handelsman DJ, Bremner WJ, McKinlay JB. Sex steroids and all-cause and cause-specific mortality in men. Arch Intern Med 2007;167:1252-1260.

17. Sueoka KT, Ewing SK, Ensrud KE, Laughlin GA, Hoffman AR, Varosy PD, et al. Higher endogenous testosterone levels associated with increased risk of coronary heart disease in elderly men: a prospective study. Endocr Rev 2010;31:S858.

18. Xu L, Freeman G, Cowling BJ, Schooling CM. Testosterone therapy and cardiovascular events among men: a systematic review and meta-analysis of placebo-controlled randomized trials. BMC Med 2013;11:108.

19. Bhasin S, Woodhouse L, Casaburi R, Singh AB, Mac RP, Lee M, et al. Older men are as responsive as young men to the anabolic effects of graded doses of testosterone on the skeletal muscle. J Clin Endocrinol Metab 2005;90:678-688.

20. Far HR, Ågren G, Thiblin I. Cardiac hypertrophy in deceased users of anabolic androgenic steroids: an investigation of autopsy findings. Cardiovasc Pathol 2012;21:312-316.

21. Laughlin GA, Barrett-Connor E, Bergstrom J. Low serum testosterone and mortality in older men. J Clin Endocrinol Metab 2008; 93:68-75.

22. Holmboe SA, Vradi E, Jensen TK, Linneberg A, Husemoen LL, Scheike T, et al. The association of reproductive hormone levels and all-cause, cancer, and cardiovascular disease mortality in men. J Clin Endocrinol Metab 2015;100:4472-4480.

23. Haring R, Völzke H, Steveling A, Krebs A, Felix SB, Schöfl C, et al. Low serum testosterone levels are associated with increased risk of mortality in a population-based cohort of men aged 2079. Eur Heart J 2010;31:1494-1501.

24. Hsu B, Cumming RG, Naganathan V, Blyth FM, Le Couteur DG, Hirani V, et al. Temporal changes in androgens and estrogens are associated with all-cause and cause-specific mortality in older men. J Clin Endocrinol Metab 2016;101:2201-2210. 